\title{
A Comparative Study on Economy of Driving Mode for Boiler Feed Pumps
}

\author{
Xianyong Peng, Peihong Wang \\ School of Energy and Environment \\ Southeast University, SEU \\ Nanjing, Jiangsu Province, China \\ xianyongpeng@seu.edu.cn,phwang@seu.edu.cn
}

\begin{abstract}
Motor-driven and steam-driven modes are mainly driving modes of boiler feed pumps in China. A novel evaluation method based on equivalent work efficiency was put forward, and the exemplification of feed water pump driving modes of $300 \mathrm{MW}$ unit showed the feasibility and effectiveness of the method. The two driving modes of boiler feed pumps were analyzed and compared by net heat consumption rate, equivalent work efficiency rate and comprehensive cost-based coal consumption rate. The results show that the use of steam-driven pumps in $300 \mathrm{MW}$ and large units can reduce net heat consumption rate and increase the output of the unit. The operating stability and regulating performance of steam-driven pumps are improved, so steam-driven pumps should be superior to motor-driven pumps.
\end{abstract}

Keywords- boiler feed pump; thermal economy; heat consumption rate; energy value analysis; comprehensive cost-based coal consumption rate; equivalent work efficiency rate

\section{INTRODUCTION}

The boiler feed pump (BFP) is one of the most important auxiliary equipments in coal-fired power plants. With the increase in steam parameters of thermodynamic cycle and the growth of unit capacity, the power capacity of boiler feed pumps is also growing. The power consumption of BFP has been accounted for about $5 \%$ of power generation capacity in the large generating units [1]. The reasonable choice for boiler feed pump driving mode plays an important role in the operation economy of the entire power plant. The type and number of BFP and the design of its water supply system have a great impact on thermal efficiency and operation cost.

There are many factors which affect the driving modes of BFP, such as thermal economy and operational reliability, amount of equipment investment and complexity of the system structure, etc. Among the factors above, thermal economy is one of the most important factors when choosing the driving mode of BFP. As is well known, there are two driving types that are motor-driven and steam-driven for boiler feed pumps of $300 \mathrm{MW}$ unit. From an international viewpoint, on the one hand, the designers and owners of coal-fired power plants in Western European countries tend to adopt motor-driven pumps system to feed water for boiler [2], on the other hand, other people such as American, Russian and Japanese consider that steam-driven mode is superior to motor-driven mode [3-7]. The reasons for the former choice are that internal efficiency of small steam turbines which drive feed water pumps in their countries is almost equivalent to the product of the efficiency of power transmission and internal efficiency of low-pressure cylinder of main steam turbine. On this premise, an integrated investment of motor-driven feed water pump system is lower than that of steam-driven feed water pump [8]. The cause of the latter choice is that the internal efficiency of the small steam turbine produced by companies in their countries has much higher than the product of the efficiency of power transmission and internal efficiency of low-pressure cylinder of main steam turbine. In other word, the net output of generating unit which has steam-driven feed water pumps is more than that of the same generating unit which feed water system is driven by electromotor.

The aim of this work is to find a new method called equivalent work efficiency rate to evaluation thermal economy of the two main feed water pump driving modes in China, furthermore, to compare the evaluation thermal economy of the two main feed water pump driving modes which applied with the method and the heat consumption rate and comprehensive cost-based coal consumption rate [9] based on the principle of energy value analysis [10].

\section{COMPARISON OF THEIR HEAT CONSUMPTION RATE}

\section{A. Description of heat consumption rate}

Generally speaking, heat consumption rate (HR) is the key indicator to determine thermal economy of thermodynamic cycle and operation of the turbine generator unit. From different point of view, it has two expression forms, one known as the gross heat rate, and the other called the net heat rate.

Heat consumption rate is defined as the amount heat which generated $1 \mathrm{kWh}$ electricity by generating unit. For different thermodynamic cycle, the formula of heat rate has different expression forms. To the intermediate reheating unit whose boiler water is fed by motor-driven pump, the gross heat consumption rate can be expressed as Formula 1.

$$
H R=\frac{q_{0}\left(h_{0}-h_{f w}\right)+q_{r h}\left(h_{r h}-h_{h}\right)}{P_{G}} .
$$

The net heat consumption rate can be expressed as Formula 2.

National Natural Science Foundation of China (No. 50376011) and Research

Fund for the Doctoral Program of Higher Education (No. 20060286033) 


$$
H R=\frac{q_{0}\left(h_{0}-h_{f w}\right)+q_{r h}\left(h_{r h}-h_{h}\right)}{P_{G}-P_{f w}}
$$

To the intermediate reheating unit whose boiler water is fed by steam-driven pump, the gross and net heat consumption rate are formulated as Formula 3 and Formula 4.

$$
\begin{aligned}
& H R=\frac{q_{0}\left(h_{0}-h_{f w}\right)+q_{r h}\left(h_{r h}-h_{h}\right)}{P_{g}+P_{f w}} \\
& H R=\frac{q_{0}\left(h_{0}-h_{f w}\right)+q_{r h}\left(h_{r h}-h_{h}\right)}{P_{g}}
\end{aligned}
$$

Where HR represents gross or net heat consumption rate and $\mathrm{q}_{0}, \mathrm{q}_{\mathrm{rh}}$ are respectively inlet steam mass flow rate and reheat steam mass flow rate of main turbine, and $\mathrm{h}_{0}, \mathrm{~h}_{\mathrm{fw}}$ are main steam enthalpy and feed water enthalpy each other. $h_{r h}, h_{h}$ are respectively HP cylinder exhaust enthalpy and reheat steam enthalpy. $\mathrm{P}_{\mathrm{g}}$ is output power of generator, and $\mathrm{P}_{\mathrm{fw}}$ is driving power of feed water pump.

\section{B. Analysis and discuss of an example}

As the actual operation of generating unit and the configuration parameters of motor-driven pumps were not exactly the same in different generating unit, the net heat rate of motor-driven pump was calculated based on an average power consumption of a variety of motor-driven pumps. These thermal calculations were preformed for a plan of condensing turbine-driven pump, and then net heat consumption rates in different operation conditions were obtained. According to the average power of electromotor units and the original design gross heat rates of the generator units, the net heat consumption rates of motor-driven constant speed pumps and motor-driven variable speed pumps in the sliding pressure modes were calculated respectively after taken into account enthalpy rise in feed water pump. The calculation results of net heat consumption rates of feed water pump driven by steam and electricity of $300 \mathrm{MW}$ unit in sliding pressure mode were summarized in Table 1.

From comparison of the results in Table 1, it can be seen that:

1) Thermal economy of steam- driven pumps is better than that of motor-driven pumps in different operation loads. In particular, thermal economy of constant speed electric pump declines quickly in low loads. As their operating speed is not

TABLE I. A SUMMARY OF NET HEAT CONSUMPTION RATES OF FEED

\begin{tabular}{|c|c|c|c|c|c|}
\hline Items & MCR & $\begin{array}{c}90 \% \\
\text { MCR }^{\mathrm{a}}\end{array}$ & $\begin{array}{r}75 \% \\
\text { MCR }\end{array}$ & $\begin{array}{r}60 \% \\
\text { MCR }\end{array}$ & $\begin{array}{r}50 \% \\
\text { MCR }\end{array}$ \\
\hline steam-driven pumps & 8011.46 & 8013.29 & 8057.81 & 8162.56 & 8272.38 \\
\hline $\begin{array}{l}\text { motor-driven variable } \\
\text { speed pumps }\end{array}$ & 8021.91 & 8035.56 & 8092.95 & 8218.28 & 8331.17 \\
\hline $\begin{array}{l}\text { constant-speed } \\
\text { electric pumps }\end{array}$ & 8036.87 & 8066.89 & 8132.57 & 8275.22 & 8389.76 \\
\hline
\end{tabular}
WATER PUMP DRIVEN BY STEAM AND ELECTRICITY OF 300MW UNIT IN SLIDING PRESSURE MODE (ITS UNIT: $\mathrm{KJ} / \mathrm{KWH}$ ) adjusted, constant speed electric pumps work in the variable load by reducing the pump outlet pressure by the way of regulating flow which can be performed by altering the pump speed through a throttle valve, so that thermal efficiency of generating units in low-load declines much.

2) Compared to that of the motor-driven mode of variable speed, thermal economy of units which use steam-driven pumps to feed water in full load has increased but not significantly, and rose greatly in low load interval from $50 \%$ to $90 \%$. The main reason is that the efficiency of hydraulic coupler is much lower than that of small steam turbine (SST) driving feed water pump particularly in low load, and there are electro-mechanical loss and power transmission loss. The internal efficiency of SST changes slightly in variable load conditions, although it is lower than that of main turbine in full load. At the same time SST can drive directly feed water pumps, resulting in better thermal economy, because intermediate link of energy conversion and transmission is few.

\section{COMPARISON OF THEIR EQUIVALENT WORK EFFICIENCY}

\section{A. Definition and expression of equivalent work efficiency}

In the same conditions that mean the same unit and the same feed water flow, a direct comparison of motor-driven pumps and steam-driven pumps can be performed in the same flow, the same pump lift that means the same pump work. Relative equivalent work efficiency rate is defined that the ratio of power consumption of motor-driven pumps and electricity which can be generated in steam turbine by the equivalent enthalpy drops of the steam flow from extraction point entering into SST. This definition can reflect thermal economy of energy owned by steam and electricity. The calculation method by equivalent work efficiency is easy to understand and be performed, simultaneously avoiding the computational precision difficulty of small steam turbine exhaust enthalpy.

The equivalent work efficiency rate can be expressed as follows:

$$
\begin{aligned}
& \eta_{s p}=\frac{\mathrm{D}_{0} \mathrm{gH}}{1000 \mathrm{D}_{\mathrm{ex}} \mathrm{H}_{\mathrm{ex}} \eta_{\mathrm{e}} \eta_{\mathrm{g}}} \\
& \eta_{m p}=\frac{\mathrm{D}_{0} \mathrm{gH}}{3600 \mathrm{P}_{\mathrm{mp}}}
\end{aligned}
$$

Where $\eta_{s p}, \eta_{m p}$ represent respectively the equivalent work efficiency of steam-driven pumps and motor-driven pumps, and $\mathrm{D}_{0}$ is mass flow rate of feed water, $\mathrm{D}_{\mathrm{ex}}, \mathrm{H}_{\mathrm{ex}}$ are mass flow rate of extracting steam entering into small turbine and enthalpy drop of the steam entering from the extraction to low-

pressure cylinder exhaust outlet of main turbine. $\eta_{e}, \eta_{g}$, g are respectively mechanical efficiency of main turbine, efficiency of generator and acceleration of gravity. Pump is the power consumption of motor-driven pumps. Formula 5 is for steamdriven pump, and Formula 6 is for motor-driven pump.

In fact, the equivalent work efficiency of motor-driven pumps $\eta_{m p}$ can be calculated by Formula 6 , because the feed 
water system of generating unit can not meet the test conditions in field if some specialized instruments are not put into use. Therefore, if pump lift $\mathrm{H}$ in different operating conditions and corresponding pump efficiency $\eta_{p}$ are calculated, shaft power of main electric feed pump will be obtained by its formula that is as following.

$$
\mathrm{P}_{m p}=\frac{\mathrm{D}_{0} \mathrm{gH}}{3600 \eta_{\mathrm{p}}} .
$$

As power consumption of main feed water pump can be calculated by Formula 8 .

$$
\mathrm{P}_{\mathrm{z}}=\frac{\mathrm{P}_{m p}}{\eta_{\mathrm{l}} \eta_{\mathrm{m}} \eta_{v} \eta_{\mathrm{fe}}}
$$

So the equivalent work efficiency of motor-driven pumps can be expressed as Formula 9.

$$
\eta_{m p}=\eta_{p} \times \eta_{l} \times \eta_{m} \times \eta_{v} \times \eta_{f e}
$$

Where $\eta_{l}$ represents efficiency of the transformer and power transmission, usually equals to $98 \%$, and $\eta_{m}$ is motor efficiency and usually equals to $97 \%$, and $\eta_{v}$ is efficiency of speed gear and is gets the value of $96 \%$. Efficiency of hydraulic coupler $\eta_{f e}$ in different operating conditions generally is hard to be calculated because there are no relevant parameters measuring points, so alternative calculation method of hydraulic coupler efficiency is theoretical method that transmission efficiency of the coupler is equal to its transmission ratio.

\section{B. Analysis and discussion of comparison results}

The feed water system of the following example were composed of two main steam-driven pumps whose rated flow parameters was $50 \%$ of rated boiler feed-water capacity and electric pumps standby with speed governing and hydraulic coupler whose rated flow parameters was $50 \%$ of rated boiler feed-water capacity. Another feed water system was consisted of three electric speed governing pumps with hydraulic coupler whose rated flow parameters was $50 \%$ of the boiler rated feed water capacity(two pumps in service and one pump standby). The equivalent work efficiency of two feed water systems above were quantitatively analyzed which is the typical forms of $300 \mathrm{MW}$ units in China. The results of equivalent work efficiency in different operating conditions were summarized and shown in Table 3.

As is shown in Table 3, the equivalent work efficiency of steam-driven pumps is slightly higher than that of motor-driven pumps in full load. The conclusion does not consider power consumption of motors driving oil system of small steam turbine and these uncertainties such as operation reasonableness and complexity of system, etc. As a whole,

TABLE II. THE RESULTS OF EQUIVALENT WORK EFFICIENCY OF FEED WATER PUMPS OF 300MW UNIT IN DIFFERENT DRIVING MODES

\begin{tabular}{|l|l|l|l|l|l|l|}
\hline \multicolumn{1}{|c|}{ Items } & Unit & MCR & $\begin{array}{c}\mathbf{9 0 \%} \\
\text { MCR }^{\mathrm{b}}\end{array}$ & $\begin{array}{l}\mathbf{7 5 \%} \\
\text { MCR }\end{array}$ & $\begin{array}{c}\mathbf{6 0 \%} \\
\text { MCR }\end{array}$ & $\begin{array}{l}\mathbf{5 0 \%} \\
\text { MCR }\end{array}$ \\
\hline mass flow rate & $\mathrm{t} / \mathrm{h}$ & 1025 & 841.5 & 701.25 & 561 & 467.5 \\
\hline pump lift & $\mathrm{m}$ & 2061 & 1963 & 1525 & 1240 & 1022 \\
\hline extraction flow of SST & $\mathrm{t} / \mathrm{h}$ & 37.16 & 30.4 & 21.71 & 14.63 & 10.85 \\
\hline enthalpy drops of extraction & $\mathrm{kJ} / \mathrm{kg}$ & 781.01 & 790.55 & 784.15 & 769.08 & 751.48 \\
\hline pump efficiency & $\%$ & 82.5 & 79.5 & 75.3 & 72.6 & 69.4 \\
\hline hydraulic coupler efficiency & $\%$ & 98 & 90.8 & 80.9 & 72.2 & 65.3 \\
\hline $\begin{array}{l}\text { equivalent work efficiency } \\
\text { of steam-driven pumps }\end{array}$ & $\%$ & 74.28 & 70.14 & 64.11 & 63.09 & 59.8 \\
\hline $\begin{array}{l}\text { equivalent work efficiency } \\
\text { of motor-driven pumps }\end{array}$ & $\%$ & 73.78 & 65.87 & 55.59 & 47.83 & 41.35 \\
\hline
\end{tabular}

thermal economy of two driving modes is generally not much difference in full load.

However, the efficiency of motor-driven pumps declines relatively fast with the drop of load and the advantage of steam-driven pumps is gradually significant. This is mainly due to a big slip loss of hydraulic coupler in low load. The lower the load of pumps, the worse the speed regulation efficiency of hydraulic coupler is. Furthermore, there are electro-mechanical loss and power transmission loss. Therefore, steam-driven pump is better than motor-driven pump considering energy efficiency purely.

On the whole, thermal economy of steam-driven pumps is superior to that of motor-driven pumps for boiler feed pump of 300MW unit.

\section{COMPARISON OF COMPREHENSIVE COST-BASED COAL CONSUMPTION RATE}

The principle of energy value analysis (also called energy monetary value analysis) was put forward based on the fact that the same amount of energy which lies in different physics forms has different monetary values. For example, $1000 \mathrm{MJ}$ electricity has monetary value of 16 dollar, while $1000 \mathrm{MJ}$ coal has monetary value of 3 dollar, in other word, the monetary value of electricity is 5.33 times as that of coal. The principle of energy value analysis is beneficial to technical and economic analysis.

\section{A. Definition and expression of comprehensive cost-based coal consumption rate}

On the basis of the principle of energy value analysis, the term of comprehensive cost-based coal consumption rate (CCCR) was brought forward, and it is defined as the following expression.

$$
\mathrm{CCCR}=\frac{\text { comprehensive power generation cost }}{\text { unit price of standard coal }}
$$

Comprehensive power generation costs are made of the unit generating cost and the cost of plant electric consumption. Unit generating cost can be express as the product of standard coal consumption rate for generating and unit price of standard coal. The cost of plant electric consumption is equal to the 
product of power consumption rate and pool purchase price. So formula of CCCR can be expressed as

$$
b_{c c}=b_{1}+\eta_{c} \times K_{e c}
$$

Where $b_{1}$ is standard coal consumption rate for generating

$\eta_{c}$ is power consumption rate. $\mathrm{K}_{\mathrm{ec}}$ represents price coefficient and is defined as

$$
K_{e c}=K_{e} / K_{c} \times 10^{4}
$$

Where $\mathrm{K}_{\mathrm{e}}$ represents unit price of electricity and $\mathrm{K}_{\mathrm{c}}$ represents unit price of standard coal.

The physical meaning of CCCR is that the power consumption of standard coal when $1 \mathrm{kWh}$ electricity generated according to comprehensive generating cost.

Comprehensive cost-based coal consumption rate is a corrected expression of standard coal consumption rate of power supply considering monetary values of electricity and coal, and it reflects main comprehensive cost of generating electricity essentially.

\section{B. Analysis and discussion of compare results}

As a novel technical and economic indicator, CCCR is useful to evaluate thermal economy of these thermal systems in coal-fired power plant, such as evaluation of feed water pump driving mode and so on. The rule of feed water pump driving mode evaluation is that if CCCR of steam-driven mode is lower than that of motor-driven mode, thermal economy of steam-driven mode will be better than motor-driven mode, and in reverse order from that stated. An example of feed water pump of 300MW was taken by comparing CCCR in Table 3.

As is shown in Table 3, CCCR of steam-driven pumps is lower than that of motor-driven pumps, so thermal economy of steam-driven pumps is higher than that of motor-driven pumps for boiler feed pump of 300MW unit.

TABLE III. RESULTS OF EQUIVALENT WORK EFFICIENCY OF FEED WATER PUMPS OF 300MW UNIT IN DIFFERENT DRIVING MODES

\begin{tabular}{|l|l|l|l|}
\hline \multicolumn{1}{|c|}{ Items } & \multicolumn{1}{|c|}{ Unit } & $\begin{array}{c}\text { motor- } \\
\text { driven mode }\end{array}$ & $\begin{array}{c}\text { steam- } \\
\text { driven mode }\end{array}$ \\
\hline price of electricity & $\mathrm{RMB} / \mathrm{kWh}$ & 0.4 & 0.4 \\
\hline price of standard coal & $\mathrm{RMB} / \mathrm{t}$ & 750 & 750 \\
\hline price coefficient & & 5.33 & 5.33 \\
\hline $\begin{array}{l}\text { standard coal consumption rate for } \\
\text { generating }\end{array}$ & $\mathrm{g} / \mathrm{kWh}$ & 302 & 306 \\
\hline $\begin{array}{l}\text { plant electric consumption rate } \\
\text { standard coal consumption rate of } \\
\text { power supply }\end{array}$ & $\mathrm{g} / \mathrm{kWh}$ & 323.0 & 318.8 \\
\hline CCCR & $\mathrm{g} / \mathrm{kWh}$ & 336.7 & 327.3 \\
\hline
\end{tabular}

\section{CONCLUSIONS}

1) With the increase of unit capacity, capacity of feed water pump correspondingly will increase. The steam-driven mode of the variable-speed pumps by small steam turbine will be more and more acceptable to much more people.
2) A new term of equivalent work efficiency and a novel evaluation thermal economy method by calculating equivalent work efficiency were presented, and the exemplification of the feed water pump driving modes of 300MW units showed the feasibility and effectiveness of the method.

3) The two driving modes (i.e. steam-driven and motordriven) for boiler feed pumps of 300MW unit were analyzed and compared by heat consumption rate, equivalent work efficiency rate and CCCR.

a) The results consistently show that steam-driven mode is better than motor-driven mode in thermal economy.

b) Compared with motor-driven pumps, steam-driven pumps are good to net electrical output increases for $300 \mathrm{MW}$ unit, reducing the net heat rate of generating and CCCR.

c) The small steam turbine driving variable-speed pumps does well in declining of power consumption rate and rising of operation efficiency, thus it could replace motor-driven pumps in future.

4) The driving mode of boiler feed pump is mainly affected by thermal economy of system. Besides thermal economy of system, the driving mode of boiler feed pump also depends on a comprehensive combination of investment income, operating reliability, complexity of system structure.

\section{REFERENCES}

[1] Michael Daugherty, "Upgrading boiler feed pumps in a UK coal-fired power station”, World Pumps, vol.1, pp.28-33, January 2006

[2] R. Belmans, P. Meulemans, D. Saenen, and W. Geysen, "3MW a.c. adjustable speed pump drive for a boiler feed pump-analysis of the possible solutions and economics of its applications", Journal of Electrical and Electronics Engineering, vol.11, pp.6-12, March 1991.

[3] Flory Alan, Warburton Anthony, "Selection and operation of variable speed boiler feed pumps in a triple pressure combined cycle plant", Proceedings of the 2003 International Joint Power Generation Conference, USA. Atlanta, pp. 413-421, June 2003.

[4] J.A. Oliver, M.J. Samotyj, Y. Shakarian, and Y. Vinitsky, "Adjustablespeed drives for thermal power plant boiler feed pumps Russian and American experience", Proceedings of the 1997 IEEE International Electric Machines and Drives Conference, USA. Milwaukee, p. [d]TC2 7.1-7.3, May 1997

[5] W.H. Liu, G.Q. Yu, "Research on the experience of changing electric feedwater pump into turbine-driven feedwater pump", Fluid Machinery, vol.33, pp. 5-7, December 2005.

[6] X.W. Han, "Optimal selection of driving mode for 300MW unit feedwater pump" , Power System Engineering, vol.19, pp. 206-208, September 2003.

[7] F.X. Chen, S.Y. Liang, M.Q. Wu, "Economy analysis of the converterfed synchronous motor used for boiler feed pumps in large power plants", Proceedings of the CSEE, vol.19, pp. 51-54, October 1999.

[8] Q.F. Wang, "Option of the motive power of the domestic 300MW fossil fired unit's feedwater pump", Power Engineering, vol.17, pp. 43-46, April 1997.

[9] G.N. Chen, "Technico-economic argumentation of a feedwater pump drive-mode based on an energy value analysis", Journal of Engineering for Thermal Energy \& Power, vol.18, pp. 97-100, January 2003.

[10] Annelie Carlson, "Energy system analysis of the inclusion of monetary values of environmental damage", Biomass and Bioenergy, vol.22, pp.169-177, March 2002. 